
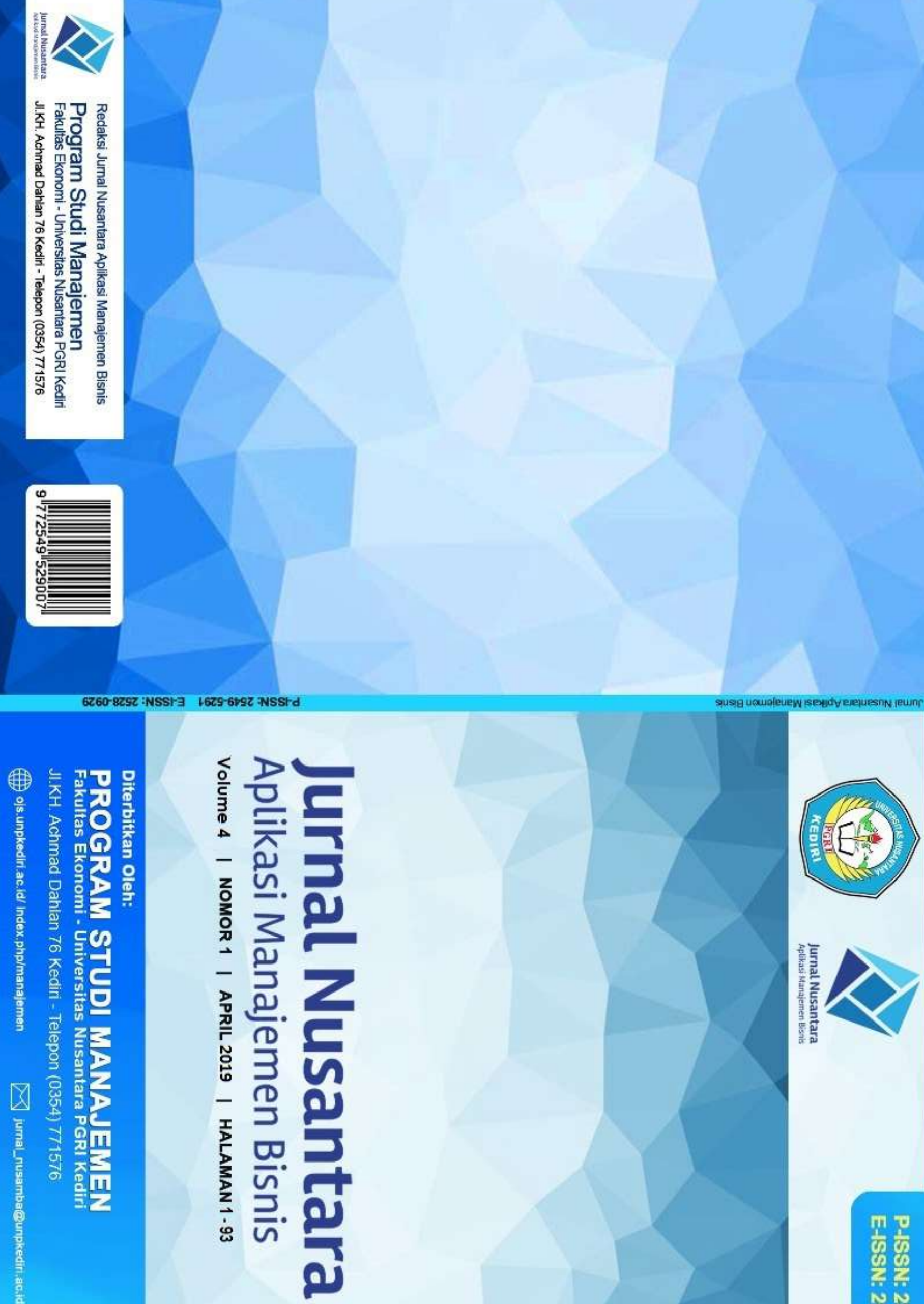
Jurnal Nusantara Aplikasi Manajemen Bisnis (NUSAMBA)

Program Studi Manajemen

Fakultas Ekonomi Universitas Nusantara PGRI Kediri

\author{
Tim Jurnal \\ Editor in Chief: \\ Diah Ayu Septi Fauji, M.M.
}

Editor:

Restin Meilina, M.M.

Editorial Reviewer:

Dr. Sentot Imam Wahjono, M.M. (Universitas Muhammadiyah Surabaya)

Dr. Indrianawati Usman, M.Si (Universitas Airlangga)

Rita Mutiarni, S.E.,M.M. (STIE PGRI Dewantara)

Nuri Purwanto, S.E., M.M. (STIE PGRI Dewantara)

\author{
Lay-out Editor: \\ Ismayantika Dyah Puspasari, M.B.A. \\ Basthoumi Muslih,M.M. \\ Proofreader: \\ Rino Sardanto, M.Pd \\ Bambang Agus Sumantri, M.M.
}

\author{
Alamat Redaksi: \\ Jurnal Nusantara Aplikasi Manajemen Bisnis \\ Prodi Manajemen \\ Fakultas Ekonomi Universitas Nusantara PGRI Kediri \\ JIn. KH. Achmad Dahlan No. 76 Kediri 64112 \\ Telepon (0354) 771576, Fax (0354) 774776 \\ Email: jurnal_nusamba@unpkediri.ac.id
}




\section{DAFTAR ISI}

Mekanisme Untuk Meningkatkan Deviden Payout Ratio Perusahaan LQ 45 - Sriyono., Nugroho, Agung. Hal. 1-16

Peran Galeri Investasi Bursa Efek Indonesia Dalam Meningkatkan Jumlah Investor dan Transaksi Efek di Jawa Timur - Murdiyanto, Edi. Hal. 17 - 27

Kepemimpinan dan Integritas Terhadap Kinerja Organisasi dengan Komitmen Organisasi sebagai Variabel Intervening - Ali, Maulana.Hal. 28- 37

Dampak Akuntabilitas, Transparansi dan Profesionalisme Pedagogik Terhadap Kinerja Guru di SMKN 21 Jakarta - Sabrudin,D., Suhendra, ES. Hal. 38 - 52

Kontribusi Gaya Kepemimpinan Terhadap Loyalitas Karyawan pada Pondok Usaha ABA Tulungagung - Anasrulloh, M., H Widya, MA. Hal. 53 - 59

Metode Topsis dalam Penilaian Kinerja Karyawan pada Sekolah Alam Auliya Kendal Aqham, AA., Febryantahanuji. Hal. 60-74

Capital Market Education Effect (Studi Kasus GI BEI UNIPDU Jombang) - Susilawati, R., Jihad, Z. Hal. 75 - 83

Studi Etnometodologi Atas Financial Management Behavour Sebagai Katalisator Efektivitas Pembelajaran Manajemen Keuangan - Puspasari, ID., Fauji,DAS. Hal. 83 - 93 


\title{
Capital Market Education Effect (Studi Kasus GI BEI Unipdu Jombang )
}

\author{
Ririn Susilawati
}

\section{Zahrul Jihad}

Universitas Pesantren Tinggi Darul Ulum

ririnraihanun@gmail.com

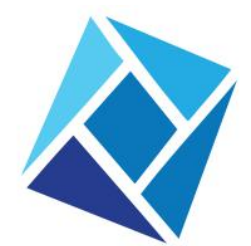

Jurnal Nusantara Aplikasi Manajemen Bisnis

http://ojs.unpkediri.ac.id/index. $\mathrm{php} / \mathrm{manajemen/index}$

E-ISSN : 2528-0929

P-ISSN : $2549-5291$

DOI

10.29407/nusamba.v4i1.12787

\section{Abstract}

Education has an influence in changing the attitude of someone in deciding something. Therefore, the success of the education applied to provide knowledge of the capital market conducted by GI BEI Unipdu Jombang has a very significant effect on the development of galleries and increasing knowledge of capital markets in the lines of academics and students. To respond to the impact of education in the Jombang GI BEI Unipdu, qualitative descriptive methods were used. the results revealed after the BEI GI education Experiencing an increase in Unipdu GI IDX investors from 2015 as many as 222 students, 2016 as many as 95 students and 2015 as many as 169 students and giving achievements in the Yuk Nabung Saham competition sent by the Indonesia Stock Exchange.

Keyword: Capital Market Education, Investment Gallery, Consumer Behavior, Islamic Boarding Schools

\section{Abstrak}

Edukasi mempunyai dampak dalam perubahan sikap sesorang dalam memutuskan sesuatu. Oleh karenanya, adanya edukasi yang diterapkan untuk memberikan pengetahuan akan pasar modal yang dilakukan oleh GI BEI Unipdu Jombang memberikan dampak yang sangat signifikan terhadap pengembagan galeri dan perluasan pengetahuan pasar modal di kalangan akademisi dan santri. Untuk menjawab dampak apa yang ditimbulkan oleh edukasi di GI BEI Unipdu Jombang digunakan metode deskrptif pendekatan kualitatif. Hasil analisis data mengungkapkan bahwa dengan adanya edukai, GI BEI Mengalami peningkatan investor GI BEI Unipdu dari tahun 2015 sebanyak 222 mahasiswa, 2016 sebanyak 95 mahasiswa dan 2015 sebanyak 169 mahasiswa serta memberikan prestasi dalam kompetisi Yuk Nabung Saham yang diadakan oleh Bursa Efek Indonesia.

Kata Kunci: Edukasi Pasar Modal, Galeri Investasi, Perilaku Konsumen, Pondok Pesantren 


\section{PENDAHULUAN}

Pasar modal hingga saat ini masih digunakan oleh sebagian kalangan dengan kriteria keilmuan yang lebih mendalam baik dari pengetahuan dasar maupun implementasi. Disisi lain masyarakat pada umumnya condong untuk berinvestasi dengan jenis sederhana seperti lahan,aurum atau logam mulia, bahkan di sebagian daerah masih ada yang menabung dalam celengan, dan tabungan serta deposito di sektor perbankan. Pada dasarnya, pasar modal menduduki fungsi sebagai perantara pihak surplus dana dengan pihak yang memerlukan dana. Word of mouth menjadi salah satu metode dalam mengenalkan pasar modal ke masyarakat. Dalam proses pengenalan, dasar pengetahuan terhadap pasar modal menjadi penting sehingga perlu adanya edukasi untuk memberikan pemahaman tersebut. Adanya edukasi akan pasar modal menjadi stimulus dalam pembuatan keputusan dengan menciptakan tidak hanya pengetahuan namun juga effort.

Adanya pengetahuan lebih yang didapatkan dari edukasi yang diberikan dapat memberikan efek langsung terhadap perubahan persepsi seseorang terhadap ssuatu sehingga dapat menjadi landasan dala pengambilan keputusan. Studi ini di ungkapkan oleh Halim dan Astuti (2015) bahwa seseorang akan memutuskan sesuatu berdasarkan pengetahuan yang dimilikinya. Pendapat yang sama dikemukakan oleh Laily (2013) yang mengatakan bahwa literasi seseorang terhadap sesuatu mempunyai pengaruh positif terhadap pengambilan keputusan. Ari dan Dewi (2014) juga beraagggapan bahwa edukasi memberikan pengaruh terhadap perubahan persepsi individu. Namun pendapat lain dikemukakan oleh Robb dan Deanna (2009) dengan hasil penelitian tidak ada kesinambungan antara pengetahuan dan prilaku aktual dalam pengambilan kepurusan. Kemudian Fernandes, et al (2014) dalam penelitiannya menyanggah hal tersebut dengan mengemukakan bahwa edukasi dalam rangka penenaman pengetahuan dini mempunyai pengaruh yang kuat terhadap perubahan tingkah laku seseorang dalam memutuskan sesuatu.

Sebagai langkah efektifitas dan efisiensi untuk mengenalkan pasar modal, Bursa Efek Indonesia melakukan pengenalan dan pendidikan/ edukasi tentang capital market dengan membuat Galeri Investasi. GI BEI adalah 
perwujudan instrumen dalam rangka mengintroduksi akademisi akan capital market. GI BEI merupakan gambaran kooperasi dari perguruan tinggi, sekuritas dan BEI dengan harapan bahwa dunia kampus merupakan wadah dalam pengenalan teori dan praktik pasar modal. Terlebih lagi saat ini GI BEI sudah masuk dan memperkenalkan pasar modal di area pondok pesantren. Hal ini tercermin dengan berdirinya Galeri Investasi BEI Unipdu Jombang. Unipdu Jombang merupakan Universitas yang terletak di tengah pondok pesantren Darul Ulum Jombang, yang saat ini tercatat sebagai satu dari sekian pesantren terbesar di Kabupaten Jombang (www.bernas.id).

Selain edukasi, untuk meningkatkan pengetahuan dan jumlah investor, BEI juga melakukan kampanye yang bertajuk "Yuk Nabung Saham". Menurut Kotler dan Roberto dalam Herman (2010), kampanye merupakan sebuah upaya persuasif untuk menanmkan ide,sikap dan perilaku terhadap target sasaran oleh suatu kelompok. Kompetisi "Yuk Nabung Saham" merupakan salah satu bentuk dari semarak yang dilakukan BEI melalui Galeri Investasi yang telah tersedia di setiap kampus seluruh Indonesia.

Dengan adanya seluruh usaha dalam mengenalkan pasar modal kepada masyarakat Dalam Penelitian ini penulis mengambil tema efek yang ditimbulkan oleh edukasi pasar modal yang dilakukan oleh GI BEI di pesantren. Kecenderungan penggunaan fasilitas GI BEI oleh mahasiswa Unipdu sendiri menjadi faktor yang melatar belakangi penelitian ini. Sedangkan faktanya terdapat pasar potensial yang dapat mengeruk investor baru di kalangan santri yang berasal dari pesantren di Jombang.

\section{METODE PENELITIAN}

Desain dalam penelitian ini adalah kualitatif dengan kaidah analisis deskriptif. Kaidah ini digunkan untuk menggambarkan secara mendalam dan terperinci tentang data yang diperoleh dari fakta empirik (Nazir, 2017) . Basis data kajian berupa data utama dan sekunde (Sugiyono,2017). Perolehan data utama bersumber pada investor dan staff GI BEI Unipdu Jombang sedangkan data sekunder diperoleh dari arsip yang telah terdokumentasi di kantor Galeri . 
Lingkup dalam kajian ini adalah Peran Edukasi Pasar Modal dalam merangsang para investor untuk aktif dalam berinvestasi di pasar modal.

\section{HASIL DAN PEMBAHASAN}

BEI memberikan mandat kepada Fakultas Ilmu Administrasi untuk mendirikan galeri investasi di Unipdu Jombang, tercatat pada bulan Oktober 2017 melalui situs resmi BEI (http://idx.co.id) ada 46 perguruan tinggi di Jawa Timur yang memiliki galeri investasi, salah satunya adalah Unipdu Jombang. Data fokus dalam penelitian ini adalah mahasiswa-mahasiswi yang mengikuti MKA Bisnis Modern dan seluruh mahasiswa-mahasiswi Fakultas Ilmu Administrasi mulai dari semester 3 sampai dengan semester 7 dengan kriteria telah mengikuti SPM dan Sosialisasi pasar modal. Dengan begitu data peningkatan Investor di GI BEI Unipdu dapat diamati.

Pada awalnya fakultas ilmu administrasi mengembangkan manajemen keuangan, manajemen keuangan ada berkembang tentang saham bagaiamana kita berinvestasi, dan bekerja sama dengan perusahaan sekuritas. Dan akhirnya didirikanlah GI BEI Unipdu, karena pengembangan dari MKA bisnis modern tentang pengembangan pasar modal. Harapannya bagaimana masyarakat umum, bukan hanya mahasiswa dan dosen saja. Negara ini butuh investasi, dan investasi ini penting dimasa depan, dan akhirnya didirikannya GI BEI Unipdu.

Tujuan didirikannya GI BEI Unipdu adalah untuk mengenalkan bagaimana investasi yang baik, agar tidak tertipu dengan investasi-investasi bodong. Langkah awal dalam proses belajar investasi adalah dengan sosialisasi. Dengan metode tersebut akan mendorong semangat mahasiswa dalam mendalami sesuatu. Sosialisasi yang dilakukan oleh GI BEI Unipdu adalah secara terbuka melalui spanduk dan cara bicara dari mulut ke mulut. Sosialisasi dilakukan setidaknya dua kali program hingga tak terhingga pertahunnya, contohnya pada tahun 2016 GI BEI Unipdu Jombang melakukan sosialisasi sabanyak 3 kali.

Respon mahasiswa-mahasiswi Unipdu pasca dilakukannya sosialisasi Pasar Modal sangat signifikan yakni 30\% s/d 50\% memutuskan untuk berinvestasi dipasar modal melalui GI BEI. Galeri memperoleh timbal balik 
dengan adanya repon positif mahasiswa, namun tidak semua mahasiswa ikut berinvestasi. Semuanya dikembalikan kepada personal mahasiswa. Pada dasarnya setiap mahasiswa memilki kecenderungan dalam keputusan berinvestasi yang berbeda-beda degan dasar kekuatan mental serta pengetahuan yang dimiliki.

Dalam sosialisasi GI BEI Unipdu untuk saat ini belum mengalami kendala teknis sama sekali, semua bisa diatasi dengan baik. Malalui GI BEI Unipdu merupakan sebuah langkah yang bagus untuk unipdu, karena bisa membawa nama unipdu sampai ke nasional. Bukan hanya ragional jawa timur, bahkan kemarin direktur utama pengembangan bursa efek Indonesia dating langsung ke Unipdu untuk melihat GI BEI Unipdu.

Untuk meningkatkan jumlah investor di GI BEI Unipdu, perlu adanya banyak inovasi dalam program dan komunikasi serta peningkatan pelayanan di galeri. Mata kuliah alternatif saja juga masih belum cukup untuk meng-cover kebutuhan akan pengetahuan yang mahasiswa inginkan, perlu dibuat sebuah komunitas belajar untuk mendukung hal tersebut.

Adanya MKA tersebut memberikan dasar teori, salah satunya perdagangan saham. Karena mitrasi edukasi pasar modal masyarakat masih sangat minim sekali, masih kalah dengan perbankkan. Padahal potensi GI BEI sangat tinggi sekali untuk memperoleh keuntungan dari sana sangat luar biasa, apalagi kalau kita mau menjadi investor dengan jangka pendek atau trader. Yang kedua Sesuai dengan fakultas fia karena didalam manajemen keuangan ada mata kuliah manajemen portofolio, analisis dan lainnya. Maka para akademisi yang mengajarkan bagaimana jika perusahaan investasi terhadap sahamnya, sehingga kita lebih ke partisi yang kita undang, baik dari bursa efek Indonesia maupun perusahaan mitra kita yaitu perusahaan sekuritas dan dalam hal ini kita menggunakan perusahaan securitas reliance securitas. Jadi memang kita lebih banyak memberikan ke lapangan bagaimana perusahaan yang menaungi kita dan bursa efek Indonesia kita juga melakukan kunjungan ke Surabaya untuk melihat lokasi. 
MKA Bisnis Modern memberikan Pengetahuan tentang pasar modal, $e$ commerce, pentingnya investasi selain menabung di bank dan managemen portofolio kepada mahasiswa-mahasiswi Unipdu. MKA Bisnis Modern memberikan edukasi yang sangat mendalam terhadap GI BEI Unipdu dan pentingnya investasi dipasar modal untuk masa depan, agar mahasiswamahasiswi Unipdu setelah selesai mengikuti MKA Bisnis Modern bisa mempraktekkan secara langsung ke lapangan.

Mengenai keputusan mahasiswa-mahasiswi Unipdu setelah mendapatkan sosialisasi tentang GI BEI Unipdu apakah memutuskan untuk berinvestasi dipasar modal atau tidak, semua kordinator dan praktisi tetap memotivasi agar mahasiswa-mahasiswi Unipdu mau untuk ikut berinvestasi di pasar modal. MKA Bisnis Modern memberikan sosialisasi dengan mendatangkan tim edukasi dari bursa efek Surabaya tentang GI BEI Unipdu dan pasar modal.

Dari tahun ketahun GI BEI Unipdu menunjukkan peningkatan dan perkembangan sekaligus tolak ukur kesuksesan yang dilakukan oleh Fakultas Ilmu Administrasi melalui sosialisasinya, selain sosialisasi yang dilakukan Fakultas Ilmu Administrasi, MKA Bisnis Modern juga sangat berperan penting dalam sosialisasi GI BEI Unipdu. Peningkatan jumlah investor ini ditunjukkan oleh data yang diperoleh dari kantor GI BEI Unipdu.

Tabel 1. Peningkatan Investor Tahun 2015-2017

\begin{tabular}{ccccccc}
\hline No & Tahun & Peningkatan & Jumlah Investor & Mahasiswa fia & Mahasiswa lain & Lainnya \\
\hline 1 & 2015 & 222 & 242 & 13 & 33 & 176 \\
2 & 2016 & 95 & 337 & 0 & 0 & 95 \\
3 & 2017 & 169 & 506 & 34 & 17 & 118 \\
\hline
\end{tabular}

Sumber : Laporan Bulanan GI BEI Unipdu Jombang

Dampak yang signifikan gambarkan oleh prestasi yang ditorehkan GI BEI Unipdu dalam Kompetisi Yuk Nabung Saham. Dari total 144 peserta Galeri Investasi, GI BEI FIA Unipdu mendapat peringkat 8 tingkat nasional untuk kategori investor aktif, dan peringkat 10 untuk kategori frekuensi transaksi. Sedangkan perwakilan dari GI BEI FIA Unipdu juga mendapatkan prestasi yang membanggakan untuk kategori jumlah portofolio terbanyak. Dengan total peserta 3.560, GI BEI FIA Unipdu menempatkan wakilnya yaitu Bambang Setyobudi di peringkat 5 dan Muhammad Rozaqi peringkat 8 tingkat nasional. 


\section{JURNAL NUSAMBA VOL. 4 NO.1 April $\mid \mathbf{2 0 1 9}$}

Dari keseluruhan data yang telah diuraikan dapat diketahui bahwa dampak edukasi yang dilakukan oleh GI BEI Unipdu sangat membawa pengaruh positif terhadap pengembangan galeri yang bisa dibilang cukup pesat. Upaya tersebut tentunya tidak

\section{PENUTUP}

Dampak Edukasi Pasar Modal di GI BEI Unipdu Jombang adalah dengang meningkatanya Investor yang tercatat di GI BEI Unipdu Jombang. Hal ini dapat dilihat dari intensitas upaya dalam mnegedukasi yang dilakukan dengan bandingan jumlah investor yang mendaftar. Sosialisasi ini dilakukan sebanyak enam kali selama 3 tahun (2015-2017). Peningkatan investor di GI BEI Unipdu 1) Pada tahun 2015 mengalami peningkatan 222 investor, sebanyak 13 mahasiswa FIA menempuh mata kuliah alternatif Bisnis Modern, sebanyak 33 mahasiswa selain FIA menempuh mata kuliah alternatif Bisnis Modern, dan 176 mahasiswa FIA dan mahasiswa lain yang tidak mengikuti MKA Bisnis Modern. 2) Pada tahun 2016 mengalami peningkatan 95 investor. 3) Pada tahun 2017 mengalami peningkatan 169 investor, sebanyak 34 mahasiswa FIA yang mengikuti MKA Bisnis Modern, sebanyak 17 mahasiswa selain FIA yang mengikuti MKA Bisnis Modern, dan 118 mahasiswa FIA dan mahasiswa lain yang tidak mengikuti MKA Bisnis Modern. Selain itu dampak edukasi mencatat Dari total 144 peserta Galeri Investasi, GI BEI FIA Unipdu mendapat peringkat 8 tingkat nasional untuk kategori investor aktif, dan peringkat 10 untuk kategori frekuensi transaksi. Sedangkan perwakilan dari GI BEI FIA Unipdu juga mendapatkan prestasi yang membanggakan untuk kategori jumlah portofolio terbanyak. Dengan total peserta 3.560, GI BEI FIA Unipdu menempatkan 
wakilnya yaitu Bambang Setyobudi di peringkat 5 dan Muhammad Rozaqi peringkat 8 tingkat nasional.

Dengan adanya pencapaian tersebut atas dampak edukasi yang dilakukan Galeri Investasi Bursa Efek Indonesia di Unipdu perlu banyak program edukasi, perlu digalakkan lagi seminar dan sosialisasi-sosialisasi tentang GI BEI Unipdu dan Pasar Modal. Tidak cukup melalui MKA saja, dibentuk sebuah Kelompok Studi Pasar Modal (KSPM) dan program terobosan selanjutnya.

\section{DAFTAR PUSTAKA}

Ari, Ida A.G.R.P., Astiti, Dewi. P. (2014). Peran Persepsi Individu Terhadap Asuransi dan Model Kepercayaan Kesehatan dalam Pengambilan Keputusan Menggunakan Asuransi Jiwa. Jurnal Psikologi Udayana. Vol.1, No. 2, 381-388. Retrivied from https://ojs.unud.ac.id/index.php/psikologi/article/view/25121/16334

Fernandes, Daniel., et al. (2014). Financial Literacy, Financial Education and Downstream Financial Behaviors. Management Sciencs from Informs Publish online. Doi: https://doi.org/10.1287/mnsc.2013.1849

Halim,Yopie K.E., Astuti, Dewi. (2015). Financial Stressors, Financial Behavior, Risk Tolerance, FInancial Solvency, Financial Knwoledge, dan Kepuasan Finansial. Finesta Vol.3, No.1 , h.19-23. Retrivied from http://publication.petra.ac.id/index.php/manajemenkeuangan/article/view /2955

Kotler, Philip dan Keller, K.L. (2009) Manajemen Pemasaran Jilid 1. Jakarta: Indeks

Laily, Najmatul. (2013). Pengaruh Literasi Keuangan Terhadap Perilaku Mahasiswa Dalam MEngelola Keuangan. Journal Of Accounting and Business. Doi : http://dx.doi.org/10.26675/jabe.v1i4.6042

Lilo, Herman., Sultan, I. (2010). Pengaruh Kampanye Program Kegiatan Sosial Partai Demokrat Terhadap Pemilih Petani Dalam Pemilu Legislatif 2009 Di Kabupaten Soppeng. Jurnal Komunikasi Kareba Vol. 1 No 2, h. 115131. http://journal.unhas.ac.id/index.php/kareba/article/view/298

Nazir, M. (2017). Metode Penelitian cetakan ke 11. Bogor: Ghalia Indonesia

Robb, Cliff. A., Sharpe, Deanna. L.(2009). Effect Of Personal Financial Knowledge on College Students's Credit Card Behavior. Jounal Of 


\section{JURNAL NUSAMBA VOL. 4 NO.1 April 2019}

Financial Counseling and Planning, Vol. 20, issue 1 No. 1,Retrivied from https://papers.ssrn.com/sol3/papers.cfm?abstract id=2224225\&download Sugiyono. (2017). Metode Penelitian Kuantitatif, Kualitatif dan R\&D. Bandung: Alfabeta

Sumarwan, Ujang. (2017). Perilaku Konsumen, Teori dan Penerapan dalam Pemasaran. Bogor: Ghalia Indonesia

Susilo, D Bambang. (2009). Pasar Modal. Yogyakarta: UPP STIM YKPN

Tandelilin, Eduardus. (2017). Pasar modal, Manajemen Portofolio dan Investasi. Yogyakarta: PT. Kanisius

www.bernas.id

www.galeriinvestasi-bei.com

www.idx.co.id 